\title{
LABORATORY EXPERIMENT OF IRON NANOPARTICLE TRANSPORT IN A ROCK FRACTURE WITH ONLINE CONCENTRATION DETECTION PROBES
}

\author{
${ }^{1}$ Milan HOKR, ${ }^{1}$ Petr PARMA, ${ }^{2}$ Filip JANKOVSKÝ, ${ }^{2}$ Milan ZUNA, ${ }^{3}$ Miloslav MRAZÍK \\ ${ }^{1}$ Technical University of Liberec, Liberec, Czech Republic, EU, milan.hokr@tul.cz \\ 2úJV Řež, a.s., Husinec, Czech Republic, EU, filip.jankovsky@ujv.cz \\ ${ }^{3}$ self-employed, Liberec, Czech Republic, EU, mmrazik@volny.cz
}

https://doi.org/10.37904/nanocon.2020.3713

\begin{abstract}
Principles, design and pilot use of a new probe for zero-valent iron nanoparticles (nZVI) concentration measurement in a micro-borehole are described in the paper. Effect of nZVI on coil inductance is known and used for such measurement before; the presented improvements relate to smaller dimensions, configuration, and electric circuit data accuracy, so that the probe can detect $\mathrm{nZVI}$ in small volume of suspension in a narrow fracture. Multichannel apparatus was made for a grid of boreholes. Test experiments were made with nZVI particles breakthrough in an artificial fracture in a granite block. The concentration is measured both by the new probe inside the block and by chemical analyses of samples at the outlet. The spontaneous particle immobilization did not allow saturation with constant concentration necessary for calibration, but within the constraints of input and output concentration and a fully submerged probe test, the quantitative sensitivity of the probe corresponds to theoretical expectations. Probe temperature dependence was also resolved.
\end{abstract}

Keywords: Nanoparticles, zero-valent iron, electromagnetic, groundwater pollution, measurement

\section{INTRODUCTION}

Process of nanoparticle transport in rock is important in many applications. In particular the use of nano zerovalent iron $(\mathrm{nZVI})$ is common for in-situ remediation and is a subject of continuing research $[1,2]$. Although generic physical mechanisms of transport are known, there is still strong interest to improve the understanding by formulation of mathematical models and their fitting to experiments [3-4], including nZVI case [5]. Obtaining spatially and temporally dense data could be very helpful to verify details of the processes.

Compared to solute tracers, it is more complicated to continuously measure the nanoparticles concentration and its spatial distribution. Magnetic properties of $\mathrm{nZVI}$ allow such option. One of the earliest uses of magnetic susceptibility sensors to measure the nZVI concentration in soil columns was [6] with own construction and [7] with commercially produced sensor Bartington MS2. The method was then improved by either more sophisticated magnetic field evaluation around the sensor coils [8], sensor movement [9] or by more accurate sensing of the coil inductance through extended discrete counting of resonance frequency and sensor movement and calibration automation [10]. The measuring coil in the cited cases was either placed outside the cylindric column, or buried in the cohesionless soil [11].

The advantage of susceptibility measurement is almost linear dependence on the zero-valent iron concentration, which is contrary to other options for spatial distribution capturing like e.g. image processing from a transparent column photos (the attempt [12] did not lead to concentration values).

Study of $n Z V I$ in rock fractures is important as they can be dominant for the transport contrary to pores and these conditions bring new challenges for experimental configuration, $\mathrm{nZVI}$ sensing, and evaluation. Only few studies have been made compared to soil materials. Experiment in $[13,14]$ injected $n Z V I$ into a chalk core with 
a single fracture in longitudinal direction, detecting the concentration commonly at the output by discrete sampling and analyses.

The use of magnetic susceptibility sensor is compromised by the access to the measured suspension volume, sensor/coil size, and sensitivity to an eventually small amount of iron. For laboratory single-fracture experiment, it means the probe packer diameter similar to common electric conductivity sensors (i.e. below $20 \mathrm{~mm}$ ) and detection of less than $1 \mathrm{~mm}$ layer of $\mathrm{nZVI}$ water suspension. As such, it could be used as a next step of granite block experiments with solute tracers and hydraulic behaviour [15].

\section{MEASURING PROBE}

\subsection{Physical principle}

Inductance $L$ of a coil is controlled by the magnetic susceptibility $\chi$ (or permeability) of the environment inside and around the coil. Iron is a ferromagnetic material, having the susceptibility by orders of magnitude larger than common rock/soil components, so controlling a coil inductance in its neighborhood. Measuring of susceptibility can be practically done by two ways: (1) mutual induction between two coaxial coils in a constantfrequency alternating current and sensing the voltage on the secondary coil by an A/D converter (this is the approach of [6] and its followers and suffer from the voltage and frequency stability and A/D conversion noise), (2) establishing a LC circuit with a fixed capacitor and measuring its resonant frequency $f$, which can be done directly in a digital form without additional conversion inaccuracy (approach of [10] and of this work).

While the $L(\chi)$ dependence is linear (for homogeneous "infinite" environment), $f(L)$ and consequently $f(\chi)$ are nonlinear but can be linearized for a reasonable range of $\mathrm{nZVI}$ concentrations - the iron in the suspension fills relatively small volume and the relative variations of frequency can be below $10^{-3}$. As the magnetic field is nonuniform, the contribution of $\chi$ from different places in/around coil is different. It can be partly concentrated to a defined volume using a ferrite core in the coil.

In case of fracture, the geometry of the space filled with iron suspension is irregular (unknown fracture aperture and coil relative position to the coarse surface) so the probe sensitivity on concentration would be placespecific. Similar situation has been shown and solved during calibration of electric conductivity sensors in a fracture, with unknown volume and geometric distribution of the electrolyte at the sensor electrodes [16].

\subsection{Technical construction}

The measuring system is composed of individual probes connected by cables to a multichannel control electronic panel (Figure 2 right), which is then connected to a PC by the serial port. The probe is a plexiglass tube adapted as a packer to $18 \mathrm{~mm}$ diameter micro-borehole. The scheme in Figure 1 shows the dimensions and the assembly from two parts glued together after installing the coil and a small printed circuit board. The plastic material is necessary to avoid influence to the measurement.

The coil has 250 turns of one lacquered wire of maximum cross-section, which fits into one chamber of the two-chamber skeleton. The coil on the skeleton is vacuum encapsulated in a ferrite half-core $\mathrm{P} 14 \times 8, \mathrm{H} 12, \mathrm{Al}$ 1500 (Figure 2 lower left). Each terminal passes through one hole in the core, the length of the terminals is 50 $\mathrm{mm}$.

Based on experience [10], the entire LC circuit (Figure 2 upper left) is integrated directly into the probe. The shaped signal is measured using a single-chip microcomputer whose clock frequency is controlled by a crystal oscillator. Time measurement resolution between signal leading edges is $10^{-6} \mathrm{~s}$.

The measuring control panel was equipped with a crystal oscillator thermostat, whose stability has key importance for the measurement accuracy. One thermometer with high resolution and stability is included, which can be attached inside or on a face of the block (with insulation from the air by e.g. foam). It provides a 
"central" temperature compensation of the magnetic susceptibility measurement. It is designed for a very narrow temperature range $\left(24-26^{\circ} \mathrm{C}\right)$ with a high resolution of $0.001^{\circ} \mathrm{C}$.

The probes and cabling were designed so that measurements could be performed on all probes simultaneously without interfering with each other, as convenient for the borehole grid. Mutual interference is prevented, among other things, by slightly different operating frequencies of the individual probes.

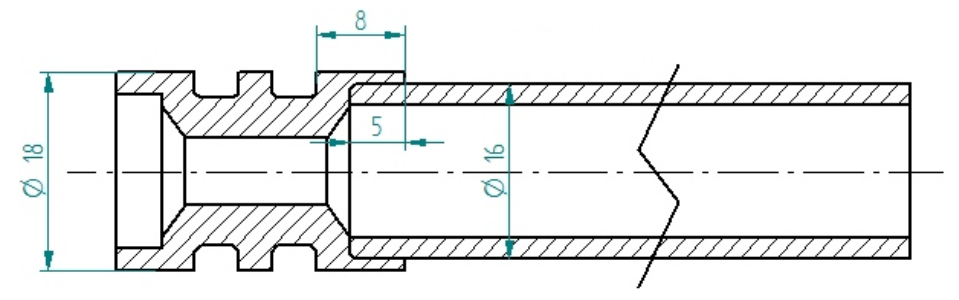

Figure 1 Drawing of the probe housing of two attached parts: The left part contains the ferrite cup (14 mm diameter) and the coil inside and rubber rings around. The right part is for electronics emplacement and cabling. Dimensions in mm.
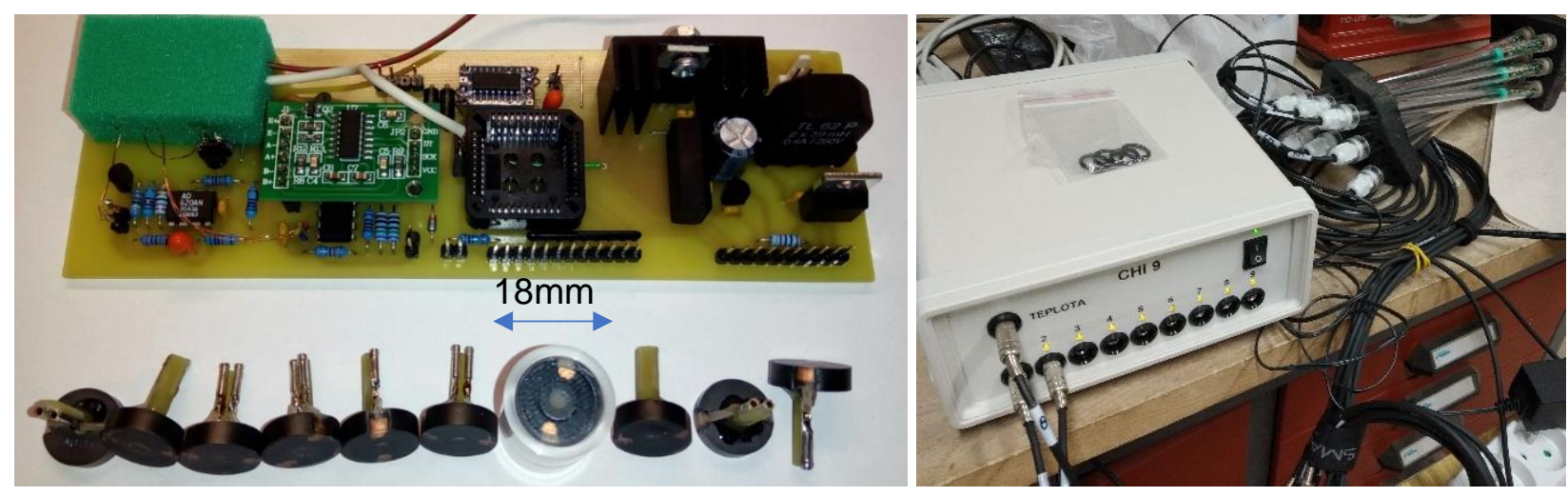

Figure 2 Printed circuit board of the analogue processing inside the probe, measuring coils in ferrite cups (one of them inside the plexiglass housing), and the completed multichannel apparatus

\subsection{Calibration tests}

Preliminary verifications included the temperature dependence for application of a correction and the dependence on $\mathrm{nZVI}$ concentration for a fully submerged probe (calibration). The temperature dependence was tested in a beaker with water freely placed in a room, i.e. with uncontrolled temperature change during gradual equilibration. The beaker is moderately stirred to enhance equilibration of the water and the probe. The evolution of temperature and frequency is plotted in Figure 3 (left), together with evolution of frequency processed by a linear correction.

The desired relation of $\mathrm{nZVI}$ concentration and resonant frequency change was verified as follows: $\mathrm{A}$ beaker with $100 \mathrm{ml}$ of demineralized water was immersed in about 5 liters of water in a PUR foam container. After the temperature and the probe signal had stabilized, $0.1 \mathrm{~mL}$ of a source suspension $(100 \mathrm{~g} / \mathrm{L})$ was injected into the beaker 10 times, making the steps of $0.1 \mathrm{~g} / \mathrm{L}$ in the measured concentration. The storage vessel was shaken before each injection. The injection time interval was chosen so that the signal always stabilized after injection. The beaker was permanently stirred moderately. The result is in Figure $\mathbf{3}$ (right).

I can be seen, that the effect of temperature in about $1{ }^{\circ} \mathrm{C}$ range is of similar magnitude as the intended measuring range for $1 \mathrm{~g} / \mathrm{L}$ concentration. Therefore, either a very good temperature stabilization is needed for the experiment (variation in hundredths of Kelvin) or a compensation must be made, for which the system is equipped. 

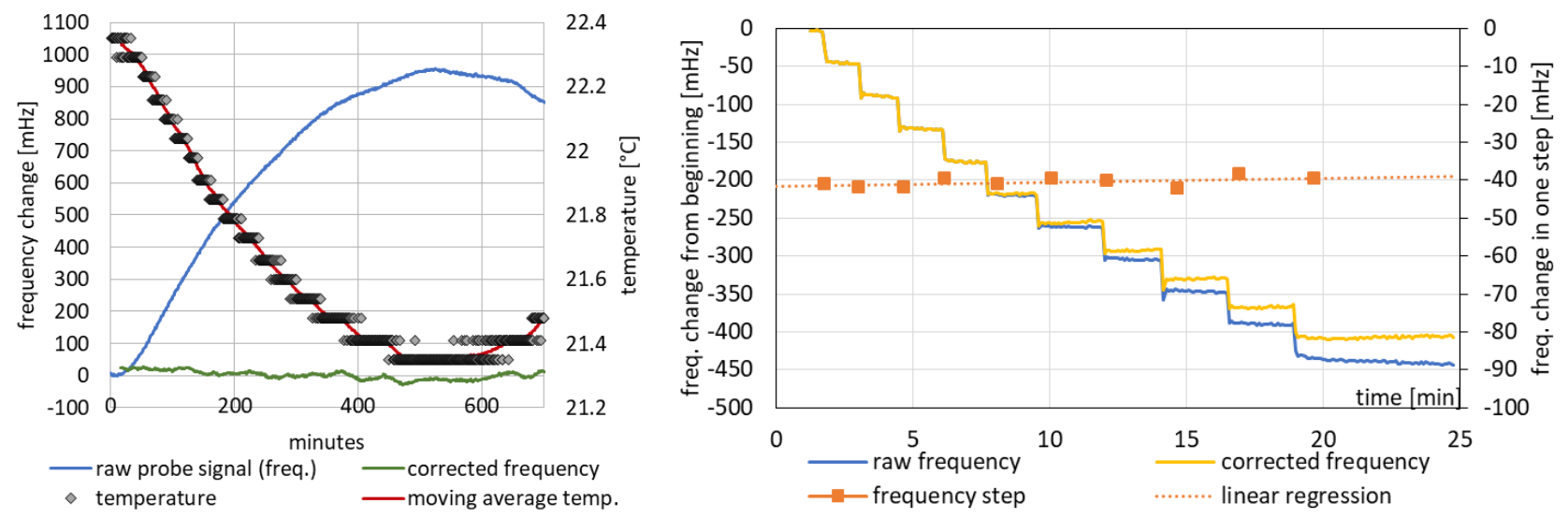

Figure 3 Verification of sensor operation and properties: Left is the temperature dependence of the probe output in pure water with linear compensation. Right is the dependence of probe output on the nZVI concentration in the beaker demonstrating the linearity between concentration and frequency.

\section{PILOT EXPERIMENT}

\subsection{Materials: iron nanoparticles and granite block}

Nanoparticles manufactured by Nanoiron (Rajhrad, Czech R.) and sold under the trade name Nanofer $25 \mathrm{~S}$ [17] were used for pilot experiments. This product contains $20 \%(\mathrm{w} / \mathrm{w})$ elemental iron nanoparticles and an organic modifier to prevent particle aggregation.

Before the actual application, the product was diluted with tempered water to a final concentration of $10 \mathrm{~g} / \mathrm{L}$ and carboxy methyl cellulose $(\mathrm{CMC})$ as a final modifier added so that its concentration was $5 \mathrm{~g} / \mathrm{L}$ in the suspension. The diluted suspension was dispersed using an IKA T 18 digital ULTRA-TURRAX disperser with a S $18 \mathrm{~N}-19 \mathrm{G}$ dispersing attachment for about 5 minutes at 20,000 rpm.

The granite block $40 \mathrm{~cm} \times 25 \mathrm{~cm} \times 20 \mathrm{~cm}(\mathrm{~L}-\mathrm{W}-\mathrm{H})$ was artificially split and reassembled. The generated approximately horizontal fracture was sealed around the perimeter (epoxy and tape). Two boreholes were drilled through the upper part (centered with respect to the width and $10 \mathrm{~cm}$ from sides in the longitudinal direction) and inlet and outlet tubes installed on the smaller vertical sides into the fracture. This granite block was also used prior to the study [15], so that the hydraulic and conservative tracer properties were known. The average aperture is approx. $0.4 \mathrm{~mm}$, i.e. $40 \mathrm{~mL}$ total void volume.

\subsection{Test procedure}

The whole laboratory was tempered several days in advance, including the experimental block and water storage tank. The dispersed suspension (necessarily heated) was equilibrated for one hour before the application. Before the $\mathrm{nZVI}$ injection, the whole volume of the fracture was flooded and washed with water. Because the signal of the probes is partly dependent on the pressure of the liquid at the front of the probe, stabilization and zeroing (autozero) was performed at a constant flow of wash water of the same value as the flow of test suspension was subsequently selected during the experiment.

During the application, the nZVI suspension was subsequently kept in buoyancy using an IKA EUROSTAR 20 digital shaft stirrer set with an R 1312 Turbine stirrer at $350 \mathrm{rpm}$. The dosing was performed using a precision laboratory peristaltic pump Ismatec IPC8 (Figure 4 left). The flow rate for the experiment was $10 \mathrm{~mL} / \mathrm{min}$. Three-way valve was used to switch between sources of pure water and nZVI suspension.

Samples were periodically taken at the outlet of the block throughout the experiment in 1 or 2 minute intervals. In these samples, the total iron content was determined (includes both the remaining suspension and Fe ions formed by reaction with water during migration). This determines the Fe balance during the experiment. 

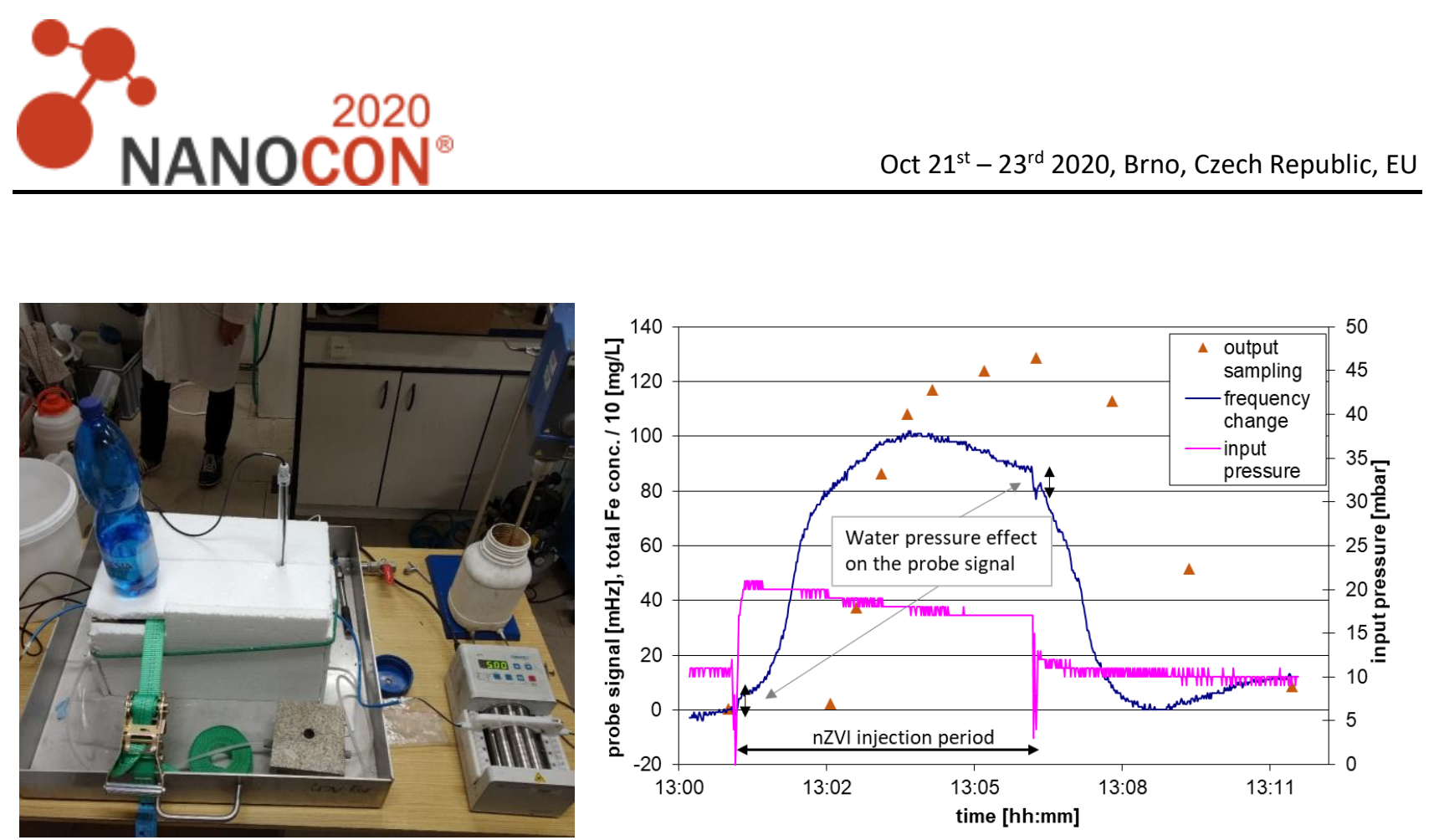

Figure 4 Experimental granite block with the measuring probe and thermal insulation. Measurement result: evolution of probe signal (10 cm from injection) and output total Fe samples ( $40 \mathrm{~cm}$ from injection). For reference, the input pressure is shown, with effect of either water or $\mathrm{nZVI}$ suspension injection.

\subsection{Results discussion}

An example of results for one of the transport tests with one probe in the borehole closer to the injection is shown in Figure 4 (right). Qualitatively, the presence of nZVI in the fracture was well detected with the probe. We did not succeed to reach fully stable probe signal with continuous injection, which can be explained by irregular effect of sedimentation or other tracer retention. Therefore we could not determine the calibration factor for defined concentration below the probe. A constraint is given from output iron concentration, whose peak is $1.2 \mathrm{~g} / \mathrm{L}$, eight times less than the injection. So the concentration at the probe is somewhere in between. Considering the sensitivity of $400 \mathrm{mHz}$ per $1 \mathrm{~g} / \mathrm{L}$ for submerged probe (a guess of $1 \mathrm{~mL}$ affected volume), the sensitivity at the fracture could be $20 \mathrm{mHz}$ per $1 \mathrm{~g} / \mathrm{L}$ (the affected volume of about $0.5 \mathrm{~mL}$ ), which would mean the peak measured concentration of $5 \mathrm{~g} / \mathrm{L}$. The calculated mass balance between input and output is approx. $15 \%$, i.e. shows a strong iron immobilization.

\section{CONCLUSION}

Based on the previous work with magnetic susceptibility measurement for nano zero-valent iron concentration determination, we designed a probe suitable for local measurement in a microborehole arrangement. The manufactured prototype was successfully tested on the granite fracture nZVI migration experiment, although the calibration with determined concentration at the probe was not possible. Even with known limitations and technical problems, this new measuring method can contribute to understanding of transport processes. At the moment, full interpretation of the test results was not subject of this paper and will continue in the following work with large block of meter scale with a grid of 9 probes.

\section{ACKNOWLEDGEMENTS}

\section{The work has been supported by Czech Technological Agency (TACR) under Project No. TH02030543.}

\section{REFERENCES}

[1] CRANE, R. A. and SCOTT, T. B.. Nanoscale zero-valent iron: Future prospects for an emerging water treatment technology. Journal of hazardous materials. 2012, vol. 211-212, pp. 112-125. 
[2] TOSCO, T., PAPINI, M. P., VIGGI, C. C. \& SETHI, R. Nanoscale zerovalent iron particles for groundwater remediation: a review. Journal of Cleaner Production. 2014, vol. 77, pp. 10-21.

[3] JAMES, S. C. \& CHRYSIKOPOULOS, C. V. Effective velocity and effective dispersion coefficient for finite-sized particles flowing in a uniform fracture. Journal of Colloid and Interface Science. 2003, vol. 263, pp. $288-295$.

[4] SALAMA, A., NEGARA A., EL AMIN M., SUN S., Numerical investigation of nanoparticles transport in anisotropic porous media. Journal of Contaminant Hydrology. 2015, vol 181, p. 114-130.

[5] MACCARI, F. Effect of suspension properties of NANOFER STAR $n Z$ VI particles on transport behavior and modeling of transport using MNMs. 2018. Master's Thesis. Universität Stuttgart - VEGAS.

[6] BUCHAU, A., DE BOER, C., KLAAS, N. \& RUCKER, W. Inductive detection and concentration measurement of nano sized zero valent iron in the subsurface. IET Science, Measurement \& Technology. 2010, vol. 4, pp. 289297.

[7] DALLA VECCHIA, E., LUNA, M. \& SETHI, R. Transport in Porous Media of Highly Concentrated Iron Micro- and Nanoparticles in the Presence of Xanthan Gum. Environmental Science \& Technology. 2009, vol. 43, pp. 89428947.

[8] LI, H., BUCHAU, A., RUCKER, W. M., KLAAS, N. \& BANUCU, R. Optimisation of a concentration measurement sensor for nano sized zero valent iron using numerical simulation. IET Science, Measurement \& Technology. 2015, vol. 9, pp. 636-643

[9] TOSCO, T., GASTONE, F. \& SETHI, R. Guar gum solutions for improved delivery of iron particles in porous media (Part 2): Iron transport tests and modeling in radial geometry. Journal of Contaminant Hydrology. 2014, vol. 166, pp. 34-51.

[10] PARMA, P. Studium migrace modifikovaných nanočástic na bázi elementárního železa (Study of migration of modified nanoparticles based on elemental iron). Czech Republic, 2018. Ph.D. Thesis. Technical University of Liberec.

[11] PEŠKOVÁ K., MIYAJIMA K., BRAUN J., ČERNÍK M. Study of the migration of nanoiron particles in the 2- and 3-D homogeneous artifical aquifer. In: NANOCON 2016 International Conference on Nanomaterials. Ostrava: Tanger, 2016, pp. 240-245.

[12] NOSEK, J. Laboratorní výzkum a modelování transportních vlastností nanoželeza (Laboratory research and modeling of nanoiron transport properties). Czech Republic, 2009. Ph.D. Thesis. Technical University of Liberec.

[13] COHEN, M., WEISBROD, N. Transport of iron nanoparticles through natural discrete fractures. Water Research, Elsevier BV. 2018, vol. 129, pp. 375-383.

[14] COHEN, M., YAKIREVICH, A. \& WEISBROD, N. The Role of Stabilizer Concentration in the Mobility of CarbonSupported Nanozerovalent Iron (nZVI) in Fractured Media. Water Resources Research. 2019, vol. 55, pp. 81648177.

[15] JANKOVSKÝ F., ZUNA M., HAVLOVÁ V., KOTOWSKI J., JANKOVEC J., HOKR M. Contaminant migration experiments in an artificial block-scale granite fracture. In: Goldschmidt 2019 conference (talk). Barcelona, 2019.

[16] KOTOWSKI J., ČERNOUŠEK T., JANKOVSKÝ F., KU゚S P., POLÍVKA P., SKALA M., KOVÁŘOVÁ H., ZUNA M. Development of Experimental Instrumentation for Measurement of Advection in Narrow Aperture in Granite Block. Journal of Nuclear Engineering and Radiation Science. 2019, vol. 5, no. 3, pp. 1-4.

[17] NANOIRON Ltd. NANOFER 25S. [online], [viewed 2020-10-19] Available from: https://nanoiron.cz/en/products/ zero-valent-iron-nanoparticles/nanofer-25s. 